\title{
Growth and physiological changes in continuously cropped eggplant (Solanum melongena L.) upon relay intercropping with garlic (Allium sativum L.)
}

\author{
Mengyi Wang, Cuinan Wu, Zhihui Cheng * and Huanwen Meng \\ College of Horticulture, Northwest A\&F University, Yangling, China
}

\section{OPEN ACCESS}

Edited by:

Rina Kamenetsky, Agricultural Research Organization the Volcani Center, Israel

Reviewed by:

Grama Nanjappa Dhanapal, University of Agricultural Sciences,

India

Jaime Prohens, Universitat Politècnica de València,

Spain

*Correspondence: Zhihui Cheng,

College of Horticulture, Northwest A\&F University, Taicheng Road No. 3 ,

Yangling, Shaanxi 712100, China chengzh@nwsuaf.edu.cn

Specialty section:

This article was submitted to Crop Science and Horticulture, a section of the journal Frontiers in Plant Science

Received: 18 January 2015 Accepted: 02 April 2015

Published: 24 April 2015

Citation:

Wang $M$, Wu C, Cheng $Z$ and Meng $H$ (2015) Growth and physiological changes in continuously cropped eggplant (Solanum melongena L.) upon relay intercropping with garlic (Allium sativum L.).

Front. Plant Sci. 6:262. doi: 10.3389/fp/s.2015.00262
Relay intercropping represents an alternative for sustainable production of vegetables, but the changes of internally antioxidant defense combined with the growth and yield are not clear. Field experiment was carried out to investigate the malondialdehyde (MDA) content and activity levels of superoxide dismutase (SOD), peroxidase (POD), polyphenol oxidase (PPO), and phenylalanine ammonia-lyase (PAL) in eggplant (Solanum melongena L.) and plant height, stem diameter, maximal leaf area, and yield of eggplant grown under successive cropping in the year 2011 and 2012 to see if relay intercropping with garlic (Allium sativum L.) could benefit to eggplant growth and yield. Three experimental treatments with three repeats in each were carried out (completely randomized block design): eggplant monoculture (CK), eggplant relay intercropping with normal garlic (NG), and eggplant relay intercropping with green garlic (GG). In both years, the MDA content was significantly lower and SOD and POD activities were generally lower in NG and GG compared with CK in most sampling dates. PPO activity trends were generally opposite to those of POD. The general trend of PAL activity was similar to MDA. The plant height and stem of eggplant was lower, but the maximal leaf area was larger in NG and GG in 2011; in 2012 the plant growth was stronger in relay intercropping treatments. For eggplant yield in 2011, NG was 2.85\% higher than CK; after the time for the green garlic pulled out was moved forward in 2012, the yield was increased by 6.26 and $7.80 \%$, respectively, in NG and GG. The lower MDA content and enzyme activities in relay intercropping treatments showed that the eggplant suffered less damage from environment and continuous cropping obstacles, which promoted healthier plant. Thus from both the growth and physiological perspective, it was concluded that eggplant/garlic relay intercropping is a beneficial cultivation practice maintaining stronger plant growth and higher yield.

\section{Keywords: malondialdehyde, superoxide dismutase, peroxidase, polyphenol oxidase, phenylalanine ammonia- lyase, growth, yield}

Abbreviations: CAT, catalase; CK, eggplant monoculture; GG, eggplant relay intercropping with green garlic; MDA, malondialdehyde; NBT, nitro blue tetrazolium; NG, eggplant relay intercropping with normal garlic; PAL, phenylalanine ammonia-lyase; POD, peroxidase; PPO, polyphenol oxidase; ROS, reactive oxygen species; SOD, superoxide dismutase; TBA, thiobarbituric acid; TCA, trichloroacetic acid. 


\section{Introduction}

Continuous cropping is a simple, repetitive agronomic practice that is often performed for vegetables cultivated under protection in China due to concerns of land-use efficiency and the cultivation habits of farmers (Xiao et al., 2012). Eggplant (Solanum melongena L.) is one of the most popular vegetables worldwide and is grown in most parts of the world. China, which is currently the largest producer of eggplant, has experienced a rapid increase in areas of protected cultivation. However, the continuous cropping of eggplant, which commonly occurs in China, can have negative effects, including increase in autotoxins in the plant which blocks its growth; decrease in resistance to bad environment; slow development; and reduce in yield and quality.

One beneficial agricultural measure that alleviates such continuous cropping obstacles is crop rotation, which is the practice of sequentially growing different crops in the same field. Crop rotation is commonly practiced to decrease the incidence of soilborne pathogens and to maintain soil fertility (Hiddink et al., 2010). However, as crop rotation rarely occurs in protected plastic tunnel systems because of the limited land area available under the plastic tunnels and Chinese farmers are accustomed to repeatedly planting the same crop in the same field, the cultivation pattern of relay intercropping has recently garnered increasing attention. Relay intercropping in mixed-cropping systems is defined as the overlapping cultivation of two or more crops in the same field, with the second crop planted when the first crop has reached its reproductive stage but has not yet been harvested (Hiddink et al., 2010). Relay intercropping is considered a practical application for basic ecological principles such as diversity, competition, and facilitation (Hauggaard-Nielsen et al., 2008), and this practice has shown enormous potential for improving soil nutrient efficiency and reducing the occurrence of plant pests, weeds, and soil-borne diseases. Especially, compared with corresponding sole crops, yield advantages have been recorded in many intercropping systems, including wheat/maize (Li et al., 2001), barley and annual medic (Sadeghpour et al., 2014), Chinese cabbages/garlic (Unlu et al., 2010), etc. Moreover, Famaye et al. (2011) found that the plant height and leaf area vegetative growth were significantly higher in the intercrops than the sole cocoa but not significantly different in all the months. Plant vigor was significantly higher in cocoa/plantain intercrop. Another study found that tomato plants intercropped with marigold or pigweed grew longer stems (26-33\%) and thinner leaves (33-35\%) than plants grown alone (Gómez-Rodríguez et al., 2007).

To maximize the effectiveness of relay intercropping, the correct combination of plants must be selected. Certain crop species, such as garlic (Allium sativum L.), onion (A. cepa L.), and welsh onion (A. fistulosum L.), have strong flavors that can repel certain pests and pathogens. Garlic is an important plant that is used worldwide as a flavoring and cover crop (Han et al., 2012), and its root exudates and shoot volatiles have a natural broadspectrum antimicrobial activity that enables this crop to protect adjacent crops from pest attacks and pathogen infection while providing negligible competition for light and water (Cheng et al., 2007). Researchers have also found that garlic root exudates have a significant inhibitory effect on Phytophthora capsici (Khan and Cheng, 2010; Khan et al., 2011).

Plants may encounter a variety of external stresses during growth, including water and salt stress and extreme temperatures. For crops under continuous cropping, additional stress arises from continuous cropping obstacles, which include the frequent occurrence of pests, the gradual accumulation of serious pathogens, decline of soil physicochemical properties, and accumulation of certain poisonous root exudates in the soil (Chen et al., 2011b). All of these stresses threaten plant growth and may cause the plant to produce reactive oxygen species (ROS), which act as early signals of a plant's defense response to external stress and serve as secondary messengers for subsequent defense reactions (Asada, 2006; Miller et al., 2007; Möller and Sweetlove, 2010; Wrzaczek et al., 2013; Yin et al., 2015), they can cause serious injury, including lipid peroxidation, membrane destruction, protein denaturation, and DNA mutation (Mittler, 2002; Davey et al., 2005; Yamauchi et al., 2008; Çelekli et al., 2013; Suleman et al., 2013).

Malondialdehyde (MDA) is a decomposition product of the polyunsaturated fatty acid hydroperoxides that are generated from reactions with ROS (Suzuki and Mittler, 2006; Tommasino et al., 2012). MDA is a reactive aldehyde, and its production may be used as a biomarker to measure the level of oxidative stress in an organism (Davey et al., 2005; Rio et al., 2005). MDA bonds with molecules such as proteins, nucleic acids, and amino acids to form insoluble compounds that can disturb cell processes and influence a plant's normal growth and development (Huang et al., 2006).

Various external stresses often induce the activity of free radical detoxification enzymes in plants (Tang et al., 2010; Rai et al., 2012). Superoxide dismutase (SOD) (EC 1.15.1.1), an important antioxidant defense enzyme and a major scavenger of $\mathrm{O}^{2-}$, catalyzes the dismutation of superoxide radical anions into $\mathrm{O}_{2}$ and $\mathrm{H}_{2} \mathrm{O}_{2}$ (Huseynova et al., 2014; Shafi et al., 2015). The highly toxic $\mathrm{H}_{2} \mathrm{O}_{2}$ is then scavenged by catalase (CAT) (EC 1.11.1.6) and peroxidase (POD) (EC 1.11.1.7). POD degrades $\mathrm{H}_{2} \mathrm{O}_{2}$ through the oxidation of cosubstrates such as phenolic compounds and/or antioxidants, thereby eliminating the deleterious effects of $\mathrm{H}_{2} \mathrm{O}_{2}$ on plants (Asada, 2006). POD activity is highly correlated with a wide range of plant physiological processes (Hiraga et al., 2001; Passardi et al., 2005; Kravić et al., 2013), including the construction and eventual lignification of cell walls, resistance to insects and pathogens, and wound healing (Moore et al., 2003; Almagro et al., 2009). Polyphenol oxidase (PPO) (monophenol, $o$-diphenol: EC 1.14.18.1, EC 1.10.3.2), another widely distributed resistance-related enzyme, is a copper-containing oxidoreductase that catalyzes two distinct reactions involving phenolic compounds and molecular oxygen. The proposed physiological roles of PPO in higher plants include producing the browning response (Richter et al., 2012), scavenging molecular oxygen in chloroplasts, participating in the plant's defense system, wound-induced rooting, and wound healing (Ramiro et al., 2006; Constabel and Barbehenn, 2008; Richter et al., 2012). Both POD and PPO are important enzymes that are responsible for the oxidation of phenolic compounds (Takahama, 2004; Doorn and Ketsa, 2014). In addition to that caused by PPO, enzymatic browning may 
result from the oxidation of phenols initiated by phenylalanine ammonia-lyase (PAL) (EC 4.3.1.5), as PAL activity in wounded tissues produces phenolic compounds that are responsible for tissue browning (Soliva-Fortuny and Martín-Belloso, 2003). PAL generally occurs at low levels in normal tissues, though its activity greatly increases upon infection and stress (Ritter and Schulz, 2004; Godinez-Vidal et al., 2008; Wada et al., 2014).

Many reports have discussed the ability of relay intercropping systems to reduce soil-borne disease and increase soil fertility ( $\mathrm{Li}$ et al., 2005; Hiddink et al., 2010; Xiao et al., 2012). However, little information is available regarding the combined effects of relay intercropping with normal garlic or green garlic on the resistance-related enzymes and the growth and yield of eggplant. Therefore, this study examines the MDA content and activities of resistance-related enzymes and the plant height, stem diameter, maximal leaf area, and yield of eggplant to determine whether relay intercropping with garlic can lead to benefits from comprehensively growth and physiological perspectives.

\section{Materials and Methods}

\section{Experimental Site}

The experiment was conducted from March 2011 to November 2012 in a plastic tunnel at Horticultural Experimental Station $\left(34^{\circ} 17^{\prime} \mathrm{N}, 108^{\circ} 04^{\prime} \mathrm{E}\right)$ of Northwest A\&F University, Yangling, Shaanxi Province, China. The annual average temperature at the study site is $12.9^{\circ} \mathrm{C}$, with extreme temperatures of $38^{\circ} \mathrm{C}$ and $-11^{\circ} \mathrm{C}$, and the frost-free period is over 200 days. Under plastic tunnels, the temperature showed parabola-like trend in both 2011 and 2012 whether the maximum or minimum temperature, and the highest temperature can reach approximately $50^{\circ} \mathrm{C}$ in Summer, and the lowest temperature is approximately $-10^{\circ} \mathrm{C}$ in Winter.

The soil characteristic at the experimental location, which is a brown, loamy, alkaline Orthic Anthrosol, was described in our previous paper (Wang et al., 2014). The $\mathrm{pH}$ of the soil is 7.8 (1:1 water), and it contains $27.02 \mathrm{~g}$ organic matter, $1.38 \mathrm{~g}$ total nitrogen, $0.96 \mathrm{~g}$ total phosphorus, and $14.31 \mathrm{~g}$ total potassium per kilogram of dry soil. In the $0-20 \mathrm{~cm}$ soil layer before eggplant transplantation, the ammonium nitrogen concentration was $57.17 \mathrm{mg} \cdot \mathrm{kg}^{-1}$, the available phosphorus was $57.65 \mathrm{mg} \cdot \mathrm{kg}^{-1}$, and the exchangeable potassium was $224.01 \mathrm{mg} \cdot \mathrm{kg}^{-1}$.

\section{Experimental Design}

Eggplant ( $S$ melongena L.) was relay intercropped as the main crop with normal garlic (NG, sowing cloves of cv. G110 in September and harvesting garlic bulbs in the next April in both years) or green garlic (GG, sowing whole bulbs of cv. G064 in July or August and harvesting green garlic three or four times within the 3 months after planting and after the green garlic had grown to approximately $30 \mathrm{~cm}$ high). The green garlic was pulled out in April in 2011 but in late March in 2012 which was the same time as eggplant transplanting because the negative effect of sunlight blocking from thick green garlic on the eggplant seedlings was found in 2011, and the time of pulling out green garlic was moved forward in 2012. Eggplant monoculture (CK) was used as the control. All the treatments were the same with our previous study (Wang et al., 2014).

The experiment was a completely randomized block design with three replications. Each plot contained two beds of $1.2 \mathrm{~m} \times 3.5 \mathrm{~m}$. In both the monoculture and relay intercropping treatments, the eggplant plants were spaced $50 \mathrm{~cm}$ apart, the rows were spaced $80 \mathrm{~cm}$ apart, and there were two rows per bed and seven plants per row. In the middle of each bed, between the two rows of eggplant, three rows of garlic cloves were planted in the NG treatment $(20 \mathrm{~cm}$ row spacing and $6 \mathrm{~cm}$ plant spacing, with 141 cloves for each bed), with four rows of garlic bulbs planted in the GG treatment (12 cm row spacing and adjacent in each row, with $8.48 \mathrm{~kg}$ bulbs for each bed). Eggplant was grown in this field for three successive years: the plants were transplanted on March 19, 2010, March 22, 2011, and March 24, 2012, and uprooted on November 25 in all three years. In 2010, the seed cloves and bulbs were planted on September 15, and the three treatments were established. The bulbs were planted on August 1, 2011 and July 20, 2012, and the cloves were planted on September 15 in both years.

Prior to eggplant transplantation, the experimental field was plowed and fertilized with $1.5 \mathrm{~kg}$ "PengDiXin" (organic matter content $\geq 30 \%, N+\mathrm{P}_{2} \mathrm{O}+\mathrm{K}_{2} \mathrm{O}$ content $\geq 4 \%$, humic acid content $\geq 20 \%$, trace element content $\geq 2 \%$, organic sylvite content $\geq 5 \%$; Zhengzhou Jinzheng Bio-chemical Co., LTD, Henan Province, China), $0.15 \mathrm{~kg}$ double superphosphate (total P content $\geq 46 \%$, available $\mathrm{P}$ content $\geq 44 \%$ ), and $0.15 \mathrm{~kg}$ "SaKeFu" compound fertilizer (total primary nutrient content $\geq 40 \%$; SinoArab Chemical Fertilizers Co., LED, Hebei Province, China) per bed. Farming management was performed following local conventions. A topdressing (a complete fertilizer called "JinBa" with humic acid content $\geq 3 \%$, trace element content $\geq 6 \%, \mathrm{~N}+\mathrm{K}_{2} \mathrm{O}$ content $\geq 18 \%$, and phosphate and $\mathrm{K}$-solubilizing agent content $\geq 5 \%$; Rishengjiufeng Biotechnology Co., LTD, Beijing, China) and irrigation were applied to each bed according to local farming conventions in both the eggplant-only period and the relay intercropping period. Irrigation but no topdressing was applied as needed for the normal garlic or green garlic during their sole cultivation (Wang et al., 2014). For eggplant, vine tying, pruning, and other farm management were administered following local conventions. During the appropriate growth stages, the eggplant plants were double-pole trained, and the vine branches were suspended from nylon ropes.

\section{Physiological Measurements Leaf Sampling}

Leaf samples were randomly collected between 10:00 and 10:30 a.m. from fully expanded leaves in the upper-middle portions of the eggplant plants, collecting one leaf per plant from six plants per treatment. Disease- and pest-free leaves were removed from the base, without the petiole. The first sampling per stubble was at 36/24 days after eggplant transplantation on April 28/17 in 2011 and 2012, respectively. Additional samples were taken on May 18/June 17 (full eggplant production after the garlic harvest), July 25/15 (5 days before planting green garlic), August 30/September 10 (15/5 days before planting normal garlic), October 9 (eggplant/garlic relay intercropping period), and 
October 30/20 (the later growth stage of eggplant) in 2011 and 2012, respectively.

Each leaf sample was placed in a plastic bag and then placed in crushed ice in a foam box immediately after collected. The surfaces of the leaves were washed with tap water and distilled water and then gently dried with absorbent paper. Afterward, the leaves were cut into pieces (omitting thick veins), packaged in aluminum foil, frozen in liquid nitrogen, and placed in a $-80^{\circ} \mathrm{C}$ ultralow temperature freezer. All of the study parameters were subsequently measured as soon as possible.

\section{MDA and Enzyme Crude Extract}

The crude extract for MDA and resistance-related enzyme, including SOD, POD, PPO, and PAL, was prepared using the methods described by Gao (2006), with some modifications. Leaf samples $(0.500 \mathrm{~g})$ were ground with $2 \mathrm{~mL}$ of cold extraction buffer (0.05 $\mathrm{M}$ phosphate buffer, $\mathrm{pH} 7.8$ ), and the entire mixture was transferred to centrifuge tubes with another $6 \mathrm{~mL}$ of the same extraction buffer and centrifuged for $20 \mathrm{~min}$ at $10,000 \times \mathrm{g}$ and $4^{\circ} \mathrm{C}$. The supernatant was used to determine the content of MDA and enzyme activities for each treatment; the measurements were performed in triplicate.

\section{Determination of MDA Content and SOD, POD, PPO, and PAL Activities}

The MDA content was measured using the thiobarbituric acid (TBA) reaction (Zhang, 2004). Two milliliter of the extract supernatant was mixed with $2 \mathrm{~mL} 0.6 \%(\mathrm{w} / \mathrm{v})$ TBA solution dissolved in $5 \%(\mathrm{v} / \mathrm{v})$ trichloroacetic acid (TCA), heated in boiling water for $10 \mathrm{~min}$, and then cooled to allow the flocculate to sediment. The supernatant was used for the spectrophotometric determination of MDA. The absorbance at the wavelength of 450 and $532 \mathrm{~nm}$ was measured and subtracted from the absorbance at $600 \mathrm{~nm}$. The MDA content was expressed as the amount of substance per gram of fresh leaves (nmol. $\left.\mathrm{g}^{-1} \mathrm{Fw}\right)$.

Total SOD activity was estimated by the inhibition of the photochemical reduction of nitro blue tetrazolium (NBT) (Gao, 2006). The reaction mixture contained $1.5 \mathrm{~mL} 0.05 \mathrm{M}$ phosphate buffer ( $\mathrm{pH} 7.8$ ), $0.3 \mathrm{~mL} \quad 0.1 \mathrm{mmol} \cdot \mathrm{L}^{-1}$ EDTA-Na $0.3 \mathrm{~mL} 0.13 \mathrm{~mol} \cdot \mathrm{L}^{-1}$ methionine, $0.3 \mathrm{~mL} 0.75 \mathrm{mmol} \cdot \mathrm{L}^{-1}$ NBT, $0.3 \mathrm{~mL} 0.02 \mathrm{mmol} \cdot \mathrm{L}^{-1}$ riboflavin, $0.05 \mathrm{~mL}$ enzymatic extract, and $0.25 \mathrm{~mL}$ distilled water in a total volume of $3 \mathrm{~mL}$ for the reaction mixture. After exposure to fluorescent light $\left(86.86 \mu \mathrm{mol} \cdot \mathrm{m}^{-2} \cdot \mathrm{s}^{-1}\right.$ ) for $10-20 \mathrm{~min}$ (endpoint determined by the color of the reaction solution), the absorbance was recorded at the wavelength of $560 \mathrm{~nm}$. SOD activity was determined as $50 \%$ inhibition of the NBT reduction caused by the superoxides generated from the reaction of photo-reduced riboflavin and oxygen. The total SOD activity was expressed in units per gram of fresh leaves $\left(\mathrm{u} \cdot \mathrm{g}^{-1} \mathrm{Fw}\right)$.

The guaiacol method was used for the determination of POD activity (Charles et al., 1998). A reaction mixture was prepared using $50 \mathrm{~mL} 0.05 \mathrm{M}$ phosphate buffer ( $\mathrm{pH} 7.8$ ), $28 \mu \mathrm{L}$ guaiacol, and $19 \mu \mathrm{L} \mathrm{30 \%} \mathrm{H}_{2} \mathrm{O}_{2}(\mathrm{v} / \mathrm{v}) ; 3.5 \mathrm{~mL}$ of the reaction mixture solution was placed into a cuvette with a $1 \mathrm{~cm}$ path length. The increase in absorbance at the wavelength of $470 \mathrm{~nm}$ was recorded over $3 \mathrm{~min}$ at $30 \mathrm{~s}$ intervals after the addition of $0.5 \mathrm{~mL}$ enzyme extract. The results were presented as $\mathrm{D}_{470}$ per minute per gram of fresh leaves $\left(\mathrm{U} \cdot \mathrm{g}^{-1} \cdot \mathrm{min}^{-1}\right)$.

PPO activity was measured spectrophotometrically by the increase in colored oxidation products within the first $3 \mathrm{~min}$ of the reaction (Zheng et al., 2007). After heating at $37^{\circ} \mathrm{C}$ for $10 \mathrm{~min}$, a mixed solution of $1.5 \mathrm{~mL} 0.05 \mathrm{M}$ phosphate buffer $(\mathrm{pH} 7.8)$ and $1.0 \mathrm{~mL} 0.1 \mathrm{~mol} \cdot \mathrm{L}^{-1}$ catechol was placed into a cuvette with a $1 \mathrm{~cm}$ path length. Immediately after the addition of $0.5 \mathrm{~mL}$ enzyme extract to initiate the reaction, the enzyme activity was measured at the wavelength of $410 \mathrm{~nm}$ every $30 \mathrm{~s}$ for $3 \mathrm{~min}$. One unit of PPO was defined as the amount of enzyme that produced a change in absorbance of $0.001 \mathrm{~min}^{-1}\left(0.001 \Delta \mathrm{A} \cdot \mathrm{min}^{-1}\right)$.

PAL activity was assayed using the procedure developed by Gao (2006). The enzyme activity was measured in a mixture (4 mL) containing $2.7 \mathrm{~mL} 0.05 \mathrm{M}$ phosphate buffer (pH 7.8), $1 \mathrm{~mL}$ $0.02 \mathrm{~mol} \cdot \mathrm{L}^{-1} \mathrm{~L}$-phenylalanine, and $0.3 \mathrm{~mL}$ enzyme extract at $30^{\circ} \mathrm{C}$ for $60 \mathrm{~min}$; and the reaction was terminated by the addition of $0.2 \mathrm{~mL} 6 \mathrm{~mol} \cdot \mathrm{L}^{-1} \mathrm{HCl}$. The final mixture was spectrophotometrically measured in a quartz cuvette at the wavelength of $290 \mathrm{~nm}$, and a unit of PAL was defined as the amount needed to produce a change in absorbance of 0.01 per hour at the wavelength of $290 \mathrm{~nm}$, which was equivalent to a $1 \mathrm{~mL}$ reaction solution forming $1 \mu \mathrm{g}$ trans-cinnamic acid $\left(\mathrm{A}_{290} \cdot \mathrm{g}^{-1} \cdot \mathrm{h}^{-1}\right)$.

\section{Eggplant Growth and Yield Record}

The morphological parameters were measured on June 20, 2011 and on June 17, 2012 which were in the most vigorous growth periods for characterizing the plant growth. Plant height was measured using tape $(0.1 \mathrm{~cm})$ and the stem diameter using electronic vernier caliper $(0.01 \mathrm{~mm})$. The maximal leaf area is represented by leaf length multiply leaf width $\left(\mathrm{cm}^{2}\right)$ of the maximal leaf. The plant height is the vertical distance from the leaf tip to the ground under natural conditions; stem diameter is measured at the widest part of the internode above cotyledons. The leaf length is measured from petiole base to blade tip and the leaf width is the extreme breadth of the maximal leaf.

Eggplant yield was recorded as the total harvest of edible mature fruits in 2011 and 2012 and presented as average per plot in kilogram per hectare $\left(\mathrm{kg} \cdot \mathrm{ha}^{-1}\right)$.

\section{Statistical Analyses}

The data of MDA content and plant enzymes obtained in this study were subjected to an analysis of variance (ANOVA), and all significant differences in physiological parameters among the monoculture and relay intercropping systems were examined according to Fisher's least significant difference (LSD) test at $P<0.05$. LSD tests were calculated using PASW Statistics 18.0 software (IBM, Armonk, NY, USA).

\section{Results}

\section{Effect of Relay Intercropping with Normal Garlic or Green Garlic on the MDA Content in Eggplant Leaves}

The overall trend of the MDA content was consistent in both 2011 and 2012: an initial increase that peaked at the blooming 


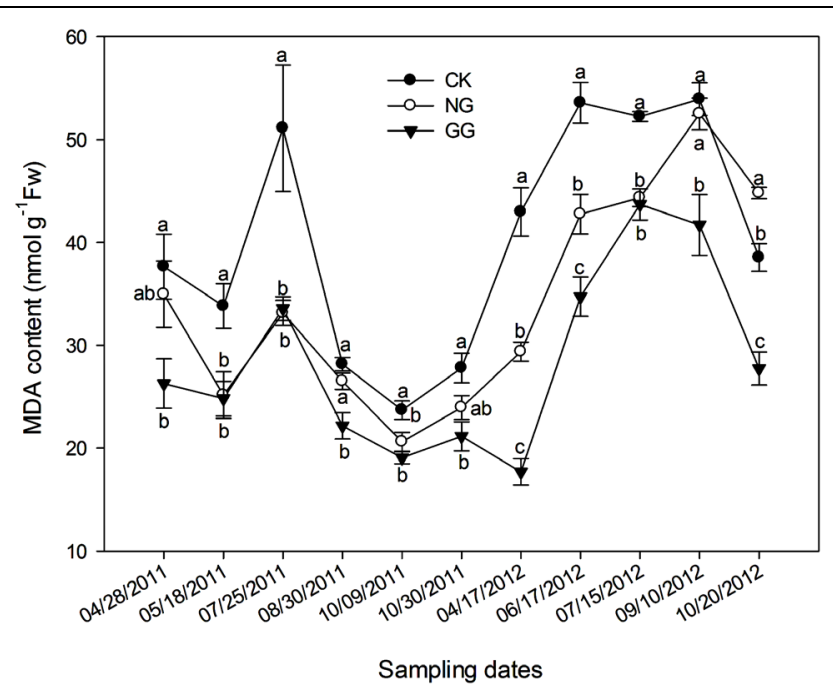

FIGURE 1 | Effect of relay intercropping with normal garlic or green garlic on the malondialdehyde (MDA) content in eggplant leaves. Error bars represent the SE of the mean. The letters $a, b$, and $c$ indicate significant differences at the $p<0.05$ level (ANOVA and LSD); $n=3$. CK, eggplant monoculture; NG,eggplant under relay intercropping with normal garlic; GG, eggplant under relay intercropping with green garlic.

and fruit-bearing stages and subsequently decreased (Figure 1), which was consistent with the seasonal changes in temperature. In both years of the experiment, the MDA content in the NG treatment was lower than that in the CK treatment on most sampling dates, with the exception of October 20, 2012. In addition, for all sampling dates, the MDA content was significantly lower in the GG treatment than in the CK treatment. The MDA content in the GG treatment was also lower than that in the NG treatment for most sampling dates, with the exception of July 25, 2011. These results indicate that eggplant under relay intercropping with normal garlic or green garlic suffered less damage from environment or continuous cropping obstacles than monocropped eggplant.

\section{Effect of Relay Intercropping with Normal Garlic or Green Garlic on SOD Activity in Eggplant Leaves}

The SOD activity in the eggplant leaf in 2011 and 2012 is shown in Figure 2A. In 2011, the SOD activity followed an M-shaped variation with an overall downward trend; in 2012, it was lowest in the April 17 samples and slowly increased after that date. In 2011, the SOD activity in the GG treatment was lower than that in the CK treatment, except on April 28, and the difference reached significance on May 18. Relay intercropping with green garlic may protect the eggplant plants against damage from the external environment, thus reducing the need to SOD activity. The SOD activity in the NG treatment was lower than that in the CK treatment before August but was higher after August 30; however, the difference between the NG and CK treatments over the entire year was not significant. For two sampling dates in 2011 - August 30 and October 9 - the SOD activity in the GG treatment was significantly lower than that in the NG treatment. More garlic was present in the GG treatment $(\sim 8.5 \mathrm{~kg})$ than in the NG treatment $(\sim 0.35 \mathrm{~kg})$; therefore, green garlic played a more important role than normal garlic in protecting the eggplant plants. In 2012, the SOD activity in the GG treatment was lower than that in the CK treatment for most sampling dates, with some dates showing significant differences. In general, the SOD activity in the relay intercropping treatments in 2012 was lower than that in the monoculture treatment. The lower SOD activity in the NG and GG treatments indicates that relay intercropping with normal garlic or green garlic could offer better protection for eggplant plants compared with monoculture-grown plants.

\section{Effect of Relay Intercropping with Normal Garlic or Green Garlic on POD Activity in Eggplant Leaves}

As shown in Figure 2B, the POD activity in 2011 initially increased and then decreased, whereas in 2012, it overall continued to increase. In 2011, the POD activity in the NG treatment was lower than that in the CK treatment for all sampling dates, and most of the differences were significant. The POD activities in the GG treatment were similar to those in the NG treatment, also lower than that in the CK, except for the sample collected on August 30. However, the POD activity in GG was not significantly different from that in $\mathrm{CK}$ for most of the sampling dates. The POD activity in all treatments reached maximum values during the fruit-bearing stage, when the temperature was high, indicating that eggplant plants may suffer a certain degree of damage under high temperatures. On October 9, the POD activity fell sharply with the decrease in temperature and then increased slightly on October 30, indicating that the eggplant plants reached the period of consenescence. In 2012, the variation trend was quite different from that in 2011. Different climate conditions in the different continuous cropping years may have caused the different growth characteristics and POD trends. Although the POD activities in the NG and GG treatments were lower than that in CK for most sampling dates in 2012, no significant differences were recorded.

\section{Effect of Relay Intercropping with Normal Garlic or Green Garlic on PPO Activity in Eggplant Leaves}

The PPO activity for the 2 years is shown in Figure 2C. In 2011, the PPO activity continually increased in the CK treatment from the seedling phase to the senescence phase. In the NG and GG treatments, however, irregular M-shaped curves were observed. The PPO activity in the NG treatment was higher than that in the CK treatment, but only on May 18, the difference between them was significant, whereas the value in the GG treatment was significantly lower than that in the CK treatment in most sampling dates except for July 25 and October 30, 2011. In 2012, the PPO activity generally followed a slow decline, but there were no significant differences between the CK and NG treatments for most of the sampling dates except that on July 15, 2012, the PPO activity in the NG was significantly higher than that in CK. In the GG treatment, the PPO activity was often lower than that in the CK treatment. In both years, the PPO activity in the GG treatment 


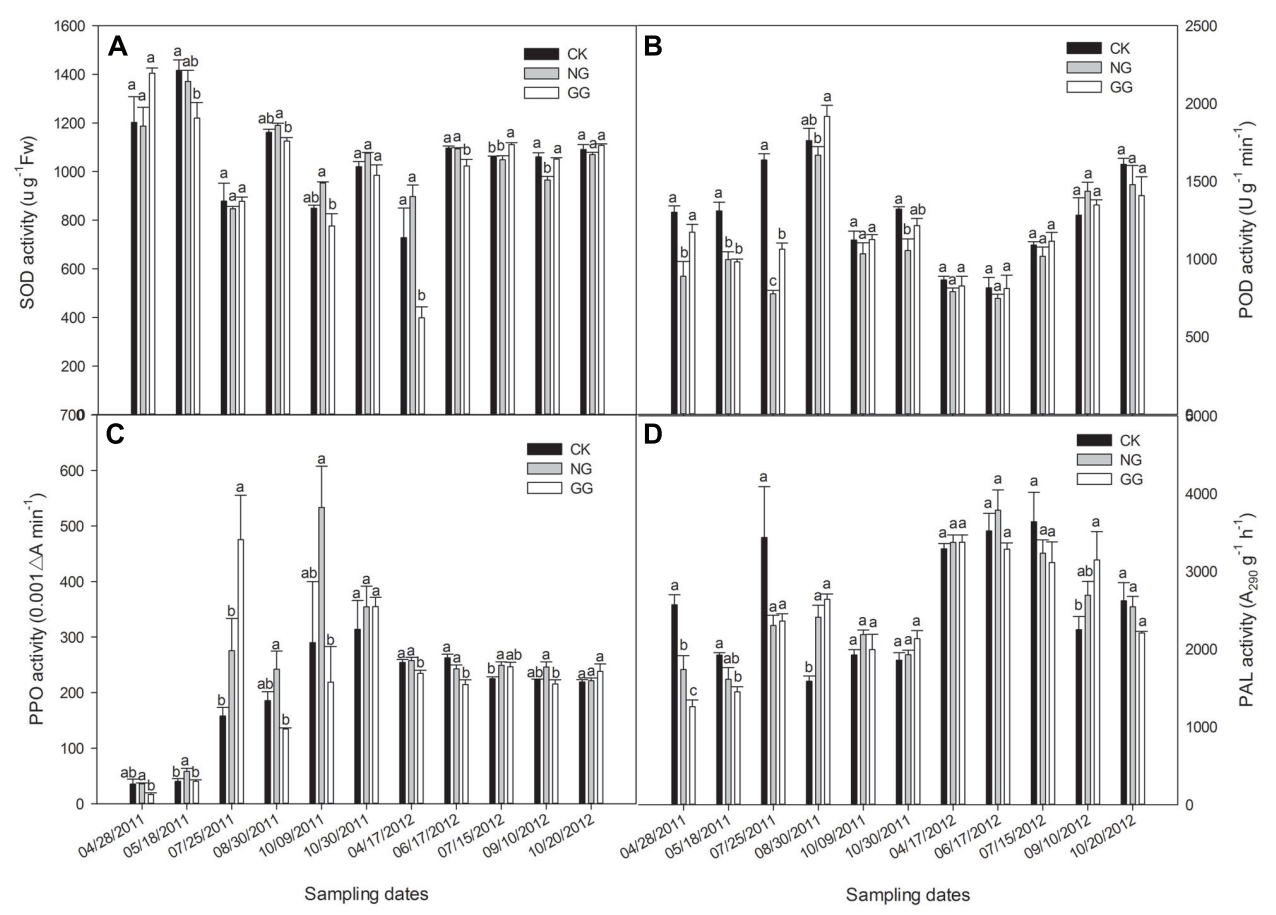

FIGURE 2 | Effects of relay intercropping with normal garlic or green garlic on superoxide dismutase (SOD) (A), peroxidase (POD) (B), polyphenol oxidase (PPO) (C) and phenylalanine ammonia-lyase (PAL) (D) activities in eggplant leaves. Error bars represent the SE of the mean.
The letters $\mathrm{a}, \mathrm{b}$, and $\mathrm{c}$ indicate significant differences at the $p<0.05$ level (ANOVA and LSD), and $n=3$. CK, eggplant monoculture; NG, eggplant under relay intercropping with normal garlic; GG, eggplant under relay intercropping with green garlic. exceeded that in the CK treatment 5 days before the green garlic was planted (July 15, 2011 and July 25, 2012) and then decreased after the green garlic took root (August 30, 2011 and September 10, 2012). This result was likely due to effects resulting from the growth of the garlic roots and its exudates.

\section{Effect of Relay Intercropping with Normal Garlic or Green Garlic on PAL Activity in Eggplant Leaves}

The overall trend for PAL activity was similar to that for the MDA content (Figure 2D). On the first three sampling dates in 2011, which was from the eggplant seedling stage to fruiting period, the PAL activity in the CK treatment was higher than that in either the NG or GG treatments. However, the opposite trend was observed over the next three sampling dates when the eggplant gradually entered the senescence stage. In 2012, although the PAL activity in the CK treatment was sometimes higher or lower than that in the other two treatments, there were no significant differences among the three treatments, except for the significantly higher PAL activity in the GG treatment on September 10 compared to that in the CK treatment. However, in both years, the PAL activity in the GG treatment was lower than that in the CK treatment 5 days before the green garlic was planted and then increased and was higher in the GG treatment than in $\mathrm{CK}$, which was opposite to the PPO. At the full-bearing stage of eggplant, the PAL activity reached its highest level during the most vigorous growth period. This increased
PAL activity may protect eggplant plants from the various external stresses caused by continuous cropping or unsuitable climate conditions.

\section{Effect of Relay Intercropping with Normal Garlic or Green Garlic on Eggplant Growth and Yield}

On June 20, 2011, the eggplant in NG treatment was a little higher than CK, but it was lower in GG than CK. On June 17, 2012, the plant in NG and GG treatments was both higher than CK (Figure 3A). For the stem diameter in Figure 3B, the eggplant was thinner in NG and GG treatments than CK in 2011, but thicker in 2012. The maximal leaf area (Figure 3C) was larger in NG and GG treatments than CK at eggplant vigorous growth stage both in 2011 and 2012 .

As shown in Table 1, in 2011, the eggplant yield in NG treatment was $2.85 \%$ higher in NG than CK, but $18.40 \%$ lower in GG. Then after moving the time of pulling out green garlic forward in 2012, the yields of both NG and GG were higher than CK, respectively, increased by 6.26 and $7.80 \%$.

\section{Discussion}

Plants suffer from many types of environmental stresses over the course of growth and development, including extreme temperatures (high temperature or low temperature) and strong daylight conditions. Continuous monoculture cultivation also results in 


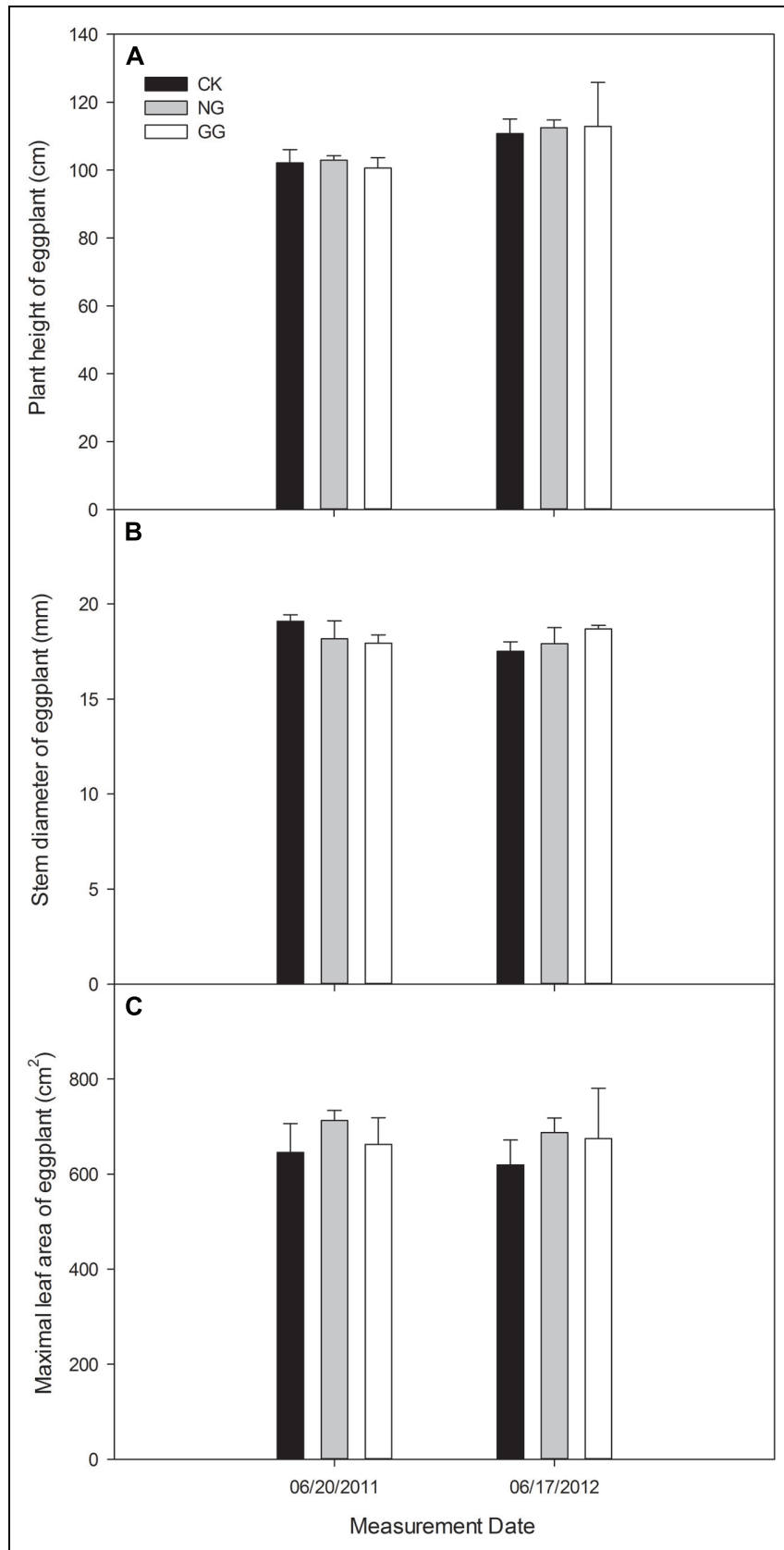

FIGURE 3 | Effects of relay intercropping with normal garlic or green garlic on the plant height (A), stem diameter (B) and maximum leaf area (C) of eggplant. Error bars represent the standard error of the mean, $n=3$. CK, eggplant monoculture; NG, eggplant under relay intercropping with normal garlic; GG, eggplant under relay intercropping with green garlic.

serious stress to plants, such as weed invasion and pest and disease infestation (Blanco and Lal, 2010). These physiological stresses can result in rapidly increasing amounts of ROS in plant cells, damaging the cellular structure and decreasing the nutritional quality of their fruit and vegetative parts (Hagerman et al., 2003; Gechev et al., 2006; Möller and Sweetlove, 2010; Singh et al., 2012; Oukarroum et al., 2015). Membrane lipid peroxidation of
TABLE 1 | Eggplant yields of the three treatments in 2011 and 2012.

\begin{tabular}{lll}
\hline Treatment & \multicolumn{2}{c}{ Yield (kg.ha-1) } \\
\cline { 2 - 3 } & $\mathbf{2 0 1 1}$ & $\mathbf{2 0 1 2}$ \\
\hline CK & $99611 \pm 2709$ & $71141 \pm 4610$ \\
NG & $102448 \pm 2601$ & $75595 \pm 5554$ \\
GG & $81282 \pm 5343$ & $76692 \pm 8338$
\end{tabular}

CK, eggplant monoculture; NG, eggplant under relay intercropping with normal garlic; GG, eggplant under relay intercropping with green garlic.

Data are presented as means $\pm S E, n=3$.

plant tissues often occurs in abiotic and senescence stresses (Chen et al., 2011a). As one of the products of membrane lipid peroxidation, MDA is correlated to the degree of membrane lipid peroxidation (Adams et al., 2008; Wu et al., 2014). The MDA content in eggplant plants relay intercropped with both normal and green garlic was lower than that in monocropped plants, indicating that relay intercropping with garlic protected the plants from damage. Moreover, for all three treatments, the MDA content reached its maximum level during the fruit-bearing period from June to August, a time when temperatures were at their highest. During this period, temperatures may exceed $50^{\circ} \mathrm{C}$ in the plastic tunnel (Wang et al., 2014); however, the physiological limit of eggplant is $35^{\circ} \mathrm{C}$, and higher temperatures cause the crop to grow slowly and develop poorly. The injuries suffered by eggplants due to high temperatures are thought to increase the MDA content. Nevertheless, the significantly lower MDA content in the relay intercropping systems shows that relay intercropping with garlic can reduce the damage suffered by eggplant and that relay intercropping can improve the plants' resistance to high temperature or other stress.

It is known that environmental stresses often induce activity for plants free-radical detoxification enzymes such as SOD and POD (Shah et al., 2001; Nahakpam and Shah, 2011; Liu and Wang, 2012; Rai et al., 2012). The producing and scavenging of ROS in cells is always in a dynamic balance, as is the activity of the enzymes responsible. SOD is the first enzyme involved in the detoxifying process that converts $\mathrm{O}_{2}{ }^{-}$- radicals to $\mathrm{H}_{2} \mathrm{O}_{2}$ at a very rapid rate (Hasan et al., 2009). During the eggplant growth stages, the SOD level varied as an irregular $\mathrm{M}$-shape in 2011. However, the SOD activity in the NG and GG treatments was lower than that in the CK treatment for most sampling dates, showing that relay intercropping with garlic can prevent the plants from being injured by pests, pathogens, or other complications of continuous cropping. There are several possible mechanisms for this phenomenon: first, garlic volatile substances or root exudates may have inhibited pests and pathogens (Wei et al., 2011); after the garlic was removed from the field, its residual root exudates may have remained, acting as allelochemicals on soil microorganisms, especially soil-borne pathogens (Khan et al., 2011). In addition, there were two sampling dates on which the SOD activity in the GG treatment was significantly lower than that in the NG treatment. The two different cultivation patterns, with different garlic densities, produced different amounts of allelochemicals, and presumably led to different protection levels, such as at the level of the spatial isolation of 
pests (Lithourgidis et al., 2011) or conidia (Gómez-Rodríguez et al., 2003), microbial antagonism (Gómez-Rodríguez et al., 2003; Khan and Cheng, 2010), or allelopathy from different volumes of root exudates (Khan et al., 2011), as reported in similar studies.

Induction of POD activity has been documented under many stress conditions such as salt stress (Chen et al., 2011a), pest damage (Dowd and Lagrimini, 2006), or pathogen injection (Melgar et al., 2006). POD is one of the most important enzymes involved in regulation of intracellular level of $\mathrm{H}_{2} \mathrm{O}_{2}$ (Hiraga et al., 2001; Passardi et al., 2005). When the plants suffer damage, more $\mathrm{O}_{2}^{-}$ would produce, and SOD could dismutate these $\mathrm{O}_{2}^{-}$; subsequently, excessive $\mathrm{H}_{2} \mathrm{O}_{2}$ induce the over expression of POD gene (Li et al., 2013). Therefore, both the SOD and POD activities would increase to avoid injury to plant cells. In this experiment, the overall trend of the SOD and POD activities were similar. In 2011, the trends were irregularly M-shaped, and in 2012, both reached their lowest values on 17 April, followed by a general increase. Moreover, as the last catalytic step in the polymerization of lignin, POD provides an important defense against the intrusion and extension of pathogens (Johrde and Schweizer, 2008; Weissinger et al., 2013). Our results showed that the POD activity in eggplant plants relay intercropped with garlic was lower than that in CK. Indeed, relay intercropping systems are known to result in less disease or other damage than monoculture systems (Suman et al., 2000; Cai et al., 2010).

POD and PPO act synergistically in enzymatic browning because PPO can promote POD activity by generating $\mathrm{H}_{2} \mathrm{O}_{2}$ from the oxidation of phenolic compounds (Tomás-Barberán and Espín, 2001; Criado et al., 2015). These enzymes play an important role in plant defense through the oxidation of endogenous phenolic compounds into quinones, which are toxic to invading pathogens and pests (Dowd et al., 2000). The resulting quinones may undergo non-enzymatic autopolymerization or covalent heterocondensation with proteins and carbohydrates to produce colored compounds (Tomás-Barberán and Espín, 2001), and these compounds may constitute a barrier against biotic and abiotic stresses (Abdel-Aal et al., 2001). Furthermore, it has been suggested that POD inhibits PPO activity (Shinshi and Noguchi, 1975). Therefore, in general, when the POD activity was higher, the PPO activity of the same sampling dates was lower. However, several complicating factors led to somewhat variable results. On June 17, 2011, both the POD and PPO activities of the CK treatment were higher than that of NG and GG treatments. As Mohammadi and Kazemi (2002) found that, the POD and PPO activities in wheat heads were increased considerably following infection by Fusarium graminearum.

Previous studies have found that additional defense systems are activated when plants suffer from damage, especially the phenylpropanoid metabolism system, and PAL activity increases rapidly (Dixon et al., 2002; Ge et al., 2014; Talbi et al., 2015). Therefore, PAL activity is an important physical indicator of a plant's ability to resist adversity. Diaz et al. (2007) found that PAL activity was significantly reduced by selenium (Se) treatments in Lactuca sativa at harvest time. Se is well known for its high potential to protect plant membranes, eradicate free particles, and delay senescence (Djanaguiraman et al., 2004; Diao et al., 2014; Hajiboland and Sadeghzade, 2014). The same theory proves that in our study, the lower PAL activity in the relay intercropping treatments showed that relay intercropping with garlic may protect eggplant biomembranes or delay senescence.

However, researchers found that PAL activity was higher in the lignified tissue of many varieties of plants, though PAL activity was not detected in the unlignified tissues of the same plants (Moller et al., 2006). In addition, some studies showed that PAL can catalyze the synthesis of anthocyanidin (Fischer et al., 2007; Yu et al., 2012), which is an important component of the color of flowers, fruits, and leaves. In this experiment, PAL activity in the CK treatment was higher than that in the NG and GG treatments in the first half of 2011. This difference may have been caused by the garlic in the field shielding the small eggplant seedlings from sunlight, thereby blocking photosynthesis and competing with the eggplant plants for nutrition, which may have caused reduced lignification and weaker eggplant growth in the relay intercropping treatments, ultimately leading to the lower yield in the GG treatment. The higher soil nutrition in NG and GG treatments in the corresponding sampling dates (Wang et al., 2014) could not be enough to save these adverse impacts. Increases in the synthesis of certain substances such as anthocyanin, is important for eggplant growth and fruit coloring, accompanies fruit development and the degree of lignification also increases, leading to increase in PAL activity. Jouili and Ferjani (2003) found that the activity of PAL, which plays an important role in plant defense, was activated under cupric stress conditions. This phenomenon occurred in the relay intercropping periods in 2012 . However, the opposite trend was observed when the eggplant gradually entered the senescence stage, which might be because in the same period, the senescence of the eggplant in NG and GG treatments was slower than that in CK, as Subrarnaniam et al. (1993) found that, the PAL activity was higher in juvenile leaf, terminal bud and caulicle of poplar, but lower in older stems and mature leaves. In addition, the parabola-like curve of PAL activity may indicate that the eggplant plants were damaged by high temperatures during the hottest days of the year, inducing increases in PAL activity to prevent injury, which is consistent with the study results of Wang (2011).

Many studies have shown that the activities of such stress resistance-related enzymes are low in healthy plants (Panina et al., 2005; Zhang et al., 2008; Hashempour et al., 2014). It reflected conversely on the crop growth and yield in 2012 that eggplant was stronger and the yield was higher in relay intercropping treatments than that in monoculture treatment, indicating that relay intercropping with garlic has stimulative effect to eggplant growth and yield. The higher activities of enzymes and MDA content observed in the eggplant leaves might indicate more injuries suffered in monoculture system, leading to weaker growth condition and lower yield, whereas healthier plant in relay intercropping systems led to stronger growth and higher yield. Furthermore, the higher soil enzyme activities and nutrients in eggplant/garlic relay intercropping systems (Wang et al., 2014) may also lead to healthier plant, and then lower plant enzyme activities and higher yield. Although in 2011, the eggplant yield in 
GG treatment was lower than that in CK because of the sunlight blocking effect of thick green garlic on the eggplant seedlings; however, after moving the time of pulling out green garlic forward in 2012, the yield in GG treatment was higher than that in CK. Although monocropping systems cause biological stress with a continuous target over time and space, intercropping systems can better control such injury by promoting biological diversity, keeping healthy plant growth and reducing the risk of crop losses.

\section{Conclusion}

The relay intercropping of eggplant with normal or green garlic is a beneficial production practice because it can alleviate the injuries to eggplant resulting from continuous cropping obstacles to the main crop and maintaining the stronger plant growth and higher yield, which provides further verification of the advantages of relay intercropping systems. Therefore, eggplant/garlic relay intercropping systems can facilitate the sustainable development of eggplant production. Furthermore, these results provide convincing evidence of the efficacy of relay intercropping that may be useful in similar systems. There were some discrepant results observed in different parameters, because the plant could be affected by many biotic and abiotic factors during its different growth periods. To more deeply understand the protection mechanism of those plant enzymes, gene expression will be done in our further study.

\section{References}

Abdel-Aal, E. S. M., Huel, P., Sosulski, F. M., Graf, R., Gillott, C., and Pietrzak, L. (2001). Screening spring wheat for midge resistence in relation to ferulic acid content. J. Agr. Food Chem. 49, 3559-3566. doi: 10.1021/jf010027h

Adams, A., De Kimpe, N., and Van Boekel, M. A. J. S. (2008). Modification of casein by the lipid oxidation product malondialdehyde. J. Agr. Food Chem. 56, 1713-1719. doi: 10.1021/jf072385b

Almagro, L., Ros, L. V. G., Belchi-Navarro, S., Bru, R., Barceló, A. R., and Pedreño, M. A. (2009). Class III peroxidases in plant defence reactions. J. Exp. Bot. 60, 377-390. doi: 10.1093/jxb/ern277

Asada, K. (2006). Production and scavenging of reactive oxygen species in chloroplasts and their functions. Plant Physiol. 141, 391-396. doi: 10.1104/pp.106.082040

Blanco, H., and Lal, R. (2010). "Cropping systems," in Principles of Soil Conservation and Management, eds H. Blanco and R. Lal (Berlin: Springer), 167-193.

Cai, H., You, M., and Lin, C. (2010). Effects of intercropping systems on community composition and diversity of predatory arthropods in vegetable fields. Acta Ecologica Sinica (in Chinese) 30, 190-195. doi: 10.1016/j.chnaes.2010.06.001

Çelekli, A., Kap $\imath$, M., and Bozkurt, H. (2013). Effect of cadmium on biomass, pigmentation, malondialdehyde, and proline of Scenedesmus quadricauda var. longispina. Bull. Environ. Contam. Toxicol. 91, 571-576. doi: 10.1007/s00128013-1100-x

Charles, S. B., Lan, R. B., and John, W. M. (1998). Localized change in peroxidase activity accompany hydrogen peroxide genereation during the deveopment of a nonhost hypersensitive reaction in lettuce. Plant Physiol. 118, 1065-1078.

Chen, Q., Zhang, M., and Shen, S. (2011a). Effect of salt on malondialdehyde and antioxidant enzymes in seedling roots of Jerusalem artichoke (Helianthus tuberosus L.). Acta Physiol. Plant 33, 273-278. doi: 10.1007/s11738-0100543-5

Chen, S., Zhou, B., Lin, S., Li, X., and Ye, X. (2011b). Accumulation of cinnamic acid and vanillin in eggplant root exudates and the relationship with continuous cropping obstacle. Afr. J. Biotechnol. 10, 2659-2665. doi: 10.5897/AJB10.1338

\section{Author Contributions}

All authors made contributions to the experiment and manuscript. MW made substantial contributions to the design of the work, the acquisition, analysis, and interpretation of data for the work and drafting the work. CW made contributions to the acquisition and analysis of date for the work and revising it critically for important intellectual content. ZC made contributions to the conception of the work and revising it critically for important intellectual content. HM made contributions to the acquisition of data for the work and revising the manuscript. All authors made contributions to the final approval of the version to be published and agreement to be accountable for all aspects of the work in ensuring that questions related to the accuracy or integrity of any part of the work are appropriately investigated and resolved.

\section{Acknowledgments}

This research was supported by a project of the National Natural Science Foundation of China (No. 31171949), the Special Fund for Agro-scientific Research in the Public Interest (No. 200903018), and the University Undergraduates Innovating Experimentation Project (No. 2201110712036). We would like to express my gratitude to Hui Dang and Mengru Zhang, who helped me during the experiment and the writing of this paper.

Cheng, Z., Jin, R., and Tong, F. (2007). Study on allelopathic effect of garlic plant volatile on cucumber seedling growth. Acta Agriculturae Boreali-occidentalis Sinica (in Chinese) 16, 149-152.

Constabel, C. P., and Barbehenn, R. (2008). "Defensive Roles of Polyphenol Oxidase in Plants," in Induced Plant Resistance to Herbivory, ed. A. Schaller (Berlin: Springer Science Business Media BV), 253-269. doi: 10.1007/978-14020-8182-8_12

Criado, M. N., Civera, M., Martínez, A., and Rodrigo, D. (2015). Use of Weibull distribution to quantify the antioxidant effect of Stevia rebaudiana on oxidative enzymes. LWT - Food Sci. Technol. 60, 985-989. doi: 10.1016/j.lwt.2014. 10.041

Davey, M., Stals, E., Panis, B., Keulemans, J., and Swennen, R. (2005). Highthroughput determination of malondialdehyde in plant tissues. Anal. Biochem. 347, 201-207. doi: 10.1016/j.ab.2005.09.041

Diao, M., Ma, L., Wang, J., Cui, J., Fu, A., and Liu, H.-Y. (2014). Selenium promotes the growth and photosynthesis of tomato seedlings under salt stress by enhancing chloroplast antioxidant defense system. J. Plant Growth Regul. 33, 671-682. doi: 10.1007/s00344-014-9416-2

Diaz, K. E., Mensuali-Sodi, A., Serra, G., Malorgio, F., Tognoni, F., Ferrante, A., et al. (2007). "Effect of selenium addition on phenylalanine ammonia-lyase (PAL) activity and ethylene production in leafy vegetables," in Proceedings of the 7th International Symposium on the Plant Hormone Ethylene, eds A. Ramina, C. Chang, J. Giovannoni, H. Klee, P. Perata, and E. Woltering (Pisa: Springer), 207-209. doi: 10.1007/978-1-4020-6014-4_43

Dixon, R., Achnine, L., Kota, P., Liu, C., Reddy, M., and Wang, L. (2002). The phenylpropanoid pathway and plant defence - a genomics perspective. Mol. Plant Pathol. 3, 371-390. doi: 10.1046/j.1364-3703.2002. 00131.x

Djanaguiraman, M., Devi, D. D., Shanker, A. K., Sheeba, J. A., and Bangarusamy, U. (2004). Impact of selenium spray on monocarpic senescence of soybean (Glycine Max L.). J. Food Agric. Environ. 2, 44-47.

Doorn, W. G. V., and Ketsa, S. (2014). Cross reactivity between ascorbate peroxidase and phenol (guaiacol) peroxidase. Postharvest Biol. Tec. 95, 64-69. doi: 10.1016/j.postharvbio.2014.04.002 
Dowd, P. F., Herms, D. A., Berhow, M. A., and Lagrimini, L. M. (2000). Mechanisms of insect resistance in transgenic plants (over) expressing a tobacco anionic peroxidase. Plant Peroxidase Newsletter 14, 93-101.

Dowd, P. F., and Lagrimini, L. M. (2006). Examination of the biological effects of high anionic peroxidase production in tobacco plants grown under field conditions. I. Insect pest damage. Transgenic Res. 15, 197-204. doi: 10.1007/s11248005-3913-9

Famaye, A. O., Iremiren, G. O., Olubamiwa, O., Aigbekaen, A. E., and Fademi, O. A. (2011). Intercropping cocoa with rice and plantain influencing cocoa morphological parameters and weed biomass. J. Agr. Sci. Tech. B 1, 745-750.

Fischer, T. C., Gosch, C., Pfeiffer, J., Halbwirth, H., Halle, C., Stich, K., et al. (2007). Flavonoid genes of pear (Pyrus communis). Trees-Struct. Funct. 21, 521-529. doi: 10.1007/s00468-007-0145-z

Gao, J. (2006). The guidance of Plant Physiology Experiments. Beijing: Higher Education Press.

Ge, Y., Guest, D. I., and Bi, Y. (2014). Differences in the induction of defence responses in resistant and susceptible muskmelon plants infected with Colletotrichum lagenarium. J. Phytopathol. 162, 48-54. doi: 10.1111/jph.12158

Gechev, T. S., Van Breusegem, F., Stone, J. M., Denev, I., and Laloi, C. (2006). Reactive oxygen species as signals that modulate plant stress responses and programmed cell death. BioEssays 28, 1091-1101. doi: 10.1002/ bies. 20493

Godinez-Vidal, D., Rocha-Sosa, M., Sepúlveda-García, E. B., Lara-Reyna, J., Rojas-Martínez, R., and Zavaleta-Mejía, E. (2008). Phenylalanine ammonia lyase activity in chilli CM-334 infected by Phytophthora capsici and Nacobbus aberrans. Eur. J. Plant Pathol. 120, 299-303. doi: 10.1007/s10658-0079215-8

Gómez-Rodríguez, O., Zavaleta-Mejía, E., González-Hernández, V. A., LiveraMuñoz, M., and Cárdenas-Soriano, E. (2003). Allelopathy and microclimatic modification of intercropping with marigold on tomato early blight disease development. Field Crop Res. 83, 27-34. doi: 10.1016/S0378-4290(03) 00053-4

Gómez-Rodríguez, O., Zavaleta-Mejía, E., González-Hernández, V. A., LiveraMuñoz, M., and Cárdenas-Soriano, E. (2007). Physiological and morphological adaptations in tomato intercropping with Tagetes erecta and Amaranthus hypochondriacus. Rev. Fitotec. Mex. 30, 421-428.

Hagerman, A. E., Dean, R. T., and Davies, M. J. (2003). Radical chemistry of epigallocatechin gallate and its relevance to protein damage. Arch. Biochem. Biophys. 414, 115-120. doi: 10.1016/S0003-9861(03)00158-9

Hajiboland, R., and Sadeghzade, N. (2014). Effect of selenium on CO2 and NO3assimilation under low and adequate nitrogen supply in wheat (Triticum aestivum L.). Photosynthetica 52, 501-510. doi: 10.1007/s11099-014-0058-1

Han, X., Cheng, Z. H., and Meng, H. W. (2012). Soil properties, nutrient dynamics, and soil enzyme activities associated with garlic stalk decomposition under various conditions. PLoS ONE 7:e50868. doi: 10.1371/journal.pone.0050868

Hasan, S., Fariduddin, Q., Ali, B., Hayat, S., and Ahmad, A. (2009). Cadmium: toxicity and tolerance in plants. J. Environ. Biol. 30, 165-174.

Hashempour, A., Ghasemnezhad, M., Ghazvini, R. F., and Sohani, M. M. (2014). Olive (Olea europaea L.) freezing tolerance related to antioxidant enzymes activity during cold acclimation and non acclimation. Acta Physiol. Plant 36, 3231-3241. doi: 10.1007/s11738-014-1689-3

Hauggaard-Nielsen, H., Jornsgaard, B., Kinane, J., and Jensen, E. S. (2008). Grain legume-cereal intercropping: the practical application of diversity, competition and facilitation in arable and organic cropping systems. Renew. Agr. Food Syst. 23, 3-12. doi: 10.1017/S1742170507002025

Hiddink, G. A., Termorshuizen, A. J., and Bruggen, A. H. C. V. (2010). "Mixed Cropping and Suppression of Soilborne Diseases," in Genetic Engineering, Biofertilisation, Soil Quality and Organic Farming, ed. E. Lichtfouse (France: Springer), 119-146. doi: 10.1007/978-90-481-8741-6_5

Hiraga, S., Sasaki, K., Ito, H., Ohashi, Y., and Matsui, H. (2001). A large family of class III plant peroxidases. Plant Cell Physiol. 42, 462-468. doi: 10.1093/pcp/pce061

Huang, Y., Liao, B., Xiao, L., Liu, S., and Wang, Z. (2006). Effects of Cd2+ on seedling growth and phytohormone contents of Glycine max. Chinese J. Environ. Sci. 27, 1398-1401.

Huseynova, I. M., Aliyeva, D. R., and Aliyev, J. A. (2014). Subcellular localization and responses of superoxide dismutase isoforms in local wheat varieties subjected to continuous soil drought. Plant Physiol. Biochem. 81, 54-60. doi: 10.1016/j.plaphy.2014.01.018

Johrde, A., and Schweizer, P. (2008). A class III peroxidase specifically expressed in pathogen-attacked barley epidermis contributes to basal resistance. Mol. Plant Pathol. 9, 687-696. doi: 10.1111/J.1364-3703.2008.00494.X

Jouili, H., and Ferjani, E. E. (2003). Changes in antioxidant and lignifying enzyme activities in sunflower roots (Helianthus annuus L.) stressed with copper excess. CR Biol. 326, 639-644. doi: 10.1016/S1631-0691(03)00157-4

Khan, M. A., and Cheng, Z. (2010). Influence of garlic root exudates on cytoMorphological alteration of the hyphae of Phytophthora capsici, the cause of Phytophthora blight in pepper. Pak. J. Bot. 42, 4353-4361.

Khan, M. A., Cheng, Z., Xiao, X., Khan, A. R., and Ahmed, S. S. (2011). Ultrastructural studies of the inhibition effect against Phytophthora capsici of root exudates collected from two garlic cultivars along with their qualitative analysis. Crop Prot. 30, 1149-1155. doi: 10.1016/j.cropro.2011.04.013

Kravić, N., Marković, K., Anđelković, V., Šukalović, V. H.-T., Babić, V., and Vuletić, M. (2013). Growth, proline accumulation and peroxidase activity in maize seedlings under osmotic stress. Acta Physiol. Plant 35, 233-239. doi: 10.1007/s11738-012-1068-x

Li, L., Sun, J. H., Zhang, F. S., Li, X. L., Yang, S. C., and Rengel, Z. (2001). Wheat/maize or wheat/soybean strip intercropping. I. Yield advantage and interspecific interactions on nutrients. Field Crop Res. 71, 123-137. doi: 10.1016/S0378-4290(01)00156-3

Li, W. X., Li, L., Sun, J. H., Guo, T. W., Zhang, F. S., and Bao, X. G. (2005). Effects of intercropping and nitrogen application on nitrate present in the profile of an orthic anthrosol in Northwest China. Agr. Ecosyst. Environ. 105, 483-497. doi: 10.1016/j.agee.2004. 07.008

Li, Y., Zhang, S., Jiang, W., and Liu, D. (2013). Cadmium accumulation, activities of antioxidant enzymes, and malondialdehyde (MDA) content in Pistia stratiotes L. Environ. Sci. Pollut. Res. 20, 1117-1123. doi: 10.1007/s11356-012-1054-2

Lithourgidis, A. S., Dordas, C. A., Damalas, C. A., and Vlachostergios, D. N. (2011). Annual intercrops: an alternative pathway for sustainable agriculture. Aust. J. Crop Sci. 5, 396-410.

Liu, Z., and Wang, X. (2012). Changes in color, antioxidant, and free radical scavenging enzyme activity of mushrooms under high oxygen modified atmospheres. Postharvest Biol. Tec. 69, 1-6. doi: 10.1016/j.postharvbio.2012.02.008

Melgar, J. C., Abney, T. S., and Vierling, R. A. (2006). Peroxidase activity in soybeans following inoculation with Phytophthora sojae. Mycopathologia 161, 37-42. doi: 10.1007/s11046-005-0721-y

Miller, G., Suzuki, N., Rizhsky, L., Hegie, A., Koussevitzky, S., and Mittler, R. (2007). Double mutants deficient in cytosolic and thylakoid ascorbate peroxidase reveal a complex mode of interaction between reactive oxygen species, plant development, and response to abiotic stresses. Plant Physiol. 144, 1777-1785. doi: $10.1104 /$ pp.107.101436

Mittler, R. (2002). Oxidative stress, antioxidants and stress tolerance. Trends Plant Sci. 7, 405-410. doi: 10.1016/S1360-1385(02)02312-9

Mohammadi, M., and Kazemi, H. (2002). Changes in peroxidase and polyphenol oxidase activities in susceptible and resistant wheat heads inoculated with Fusarium graminearum and induced resistance. Plant Sci. 162, 491-498. doi: 10.1016/S0168-9452(01)00538-6

Möller, I. M., and Sweetlove, L. J. (2010). ROS signalling - specificity is required. Trends Plant Sci. 15, 370-374. doi: 10.1016/j.tplants.2010.04.008

Moller, R., Koch, G., Nanayakkara, B., and Schmitt, U. (2006). Lignification in cell cultures of Pinas radiata: activities of enzymes and lignin topochemistry. Tree Physiol. 26, 201-210. doi: 10.1093/treephys/26.2.201

Moore, J. P., Paul, N. D., Whittaker, J. B., and Taylor, J. E. (2003). Exogenous jasmonic acid mimics herbivore-induced sytemic increase in cell wall bound peroxidase activity and reduction in leaf expansion. Funct. Ecol. 17, 549-554. doi: 10.1046/j.1365-2435.2003.00767.x

Nahakpam, S., and Shah, K. (2011). Expression of key antioxidant enzymes under combined effect of heat and cadmium toxicity in growing rice seedlings. Plant Growth Regul. 63, 23-35. doi: 10.1007/s10725-010-9508-3

Oukarroum, A., Bussotti, F., Goltsev, V., and Kalaji, H. M. (2015). Correlation between reactive oxygen species production and photochemistry of photosystems I and II in Lemna gibba L. plants under salt stress. Environ. Exp. Bot. 109, 80-88. doi: 10.1016/j.envexpbot.2014.08.005 
Panina, Y. S., Gerasimova, N. G., Chalenko, G. I., Vasyukova, N. I., and Ozeretskovskaya, O. L. (2005). Salicylic acid and phenylalanine ammonia-lyase in potato plants infected with the causal agent of late blight. Russ. J. Plant Physiol. 52, 511-515. doi: 10.1007/s11183-005-0075-9

Passardi, F., Cosio, C., Penel, C., and Dunand, C. (2005). Peroxidases have more functions than a Swiss army knife. Plant Cell Rep. 24, 255-265. doi: 10.1007/s00299-005-0972-6

Rai, A. C., Singh, M., and Shah, K. (2012). Effect of water withdrawal on formation of free radical, proline accumulation and activities of antioxidant enzymes in ZAT12-transformed transgenic tomato plants. Plant Physiol. Biochem. 61, 108-114. doi: 10.1016/j.plaphy.2012.09.010

Ramiro, D. A., Guerreiro-Filho, O., and Mazzafera, P. (2006). Phenol contents, oxidase activities, and the resistance of coffee to the leaf miner Leucoptera coffeella. J. Chem. Ecol. 32, 1977-1988. doi: 10.1007/s10886-006-9122-z

Richter, C., Dirks, M. E., Gronover, C. S., Prufer, D., and Moerschbacher, B. M. (2012). Silencing and heterologous expression of ppo-2 indicate a specific function of a singlepolyphenol oxidase isoform in resistance of dandelion (Taraxacum officinale) against Pseudomonas syringae pv. tomato. Mol. Plant Microbe In. 25, 200-210. doi: 10.1094/MPMI-04-11-0082

Rio, D. D., Stewart, A. J., and Pellegrini, N. (2005). A review of recent studies on malondialdehyde as toxic molecule and biological marker of oxidative stress. Nutr. Metab. Cardiovas. 15, 316-328. doi: 10.1016/j.numecd.2005.05.003

Ritter, H., and Schulz, G. E. (2004). Structural basis for the entrance into the phenylpropanoid metabolism catalyzed by phenylalanine ammonia-lyase. Plant Cell 16, 3426-3436. doi: 10.1105/tpc.104.025288

Sadeghpour, A., Jahanzad, E., Lithourgidis, A. S., Hashemi, M., Esmaeili, A., and Hosseini, M. B. (2014). Forage yield and quality of barley-annual medic intercrops in semi-arid environments. Int. J. Plant Prod. 8, 77-89.

Shafi, A., Gill, T., Sreenivasulu, Y., Kumar, S., Ahuja, P. S., and Singh, A. K. (2015). Improved callus induction, shoot regeneration, and salt stress tolerance in Arabidopsis overexpressing superoxide dismutase from Potentilla atrosanguinea. Protoplasma 252, 41-51. doi: 10.1007/s00709-014-0653-9

Shah, K., Kumar, R. G., Verma, S., and Dubey, R. S. (2001). Effect of cadmium on lipid peroxidation, superoxide anion generation and activities of antioxidant enzymes in growing rice seedlings. Plant Sci. 161, 1136-1144. doi: 10.1016/S0168-9452(01)00517-9

Shinshi, H., and Noguchi, M. (1975). Relationship between peroxidases, IAA oxidases and polyphenol oxidases. Phytochemistry 14, 1255-1258. doi: 10.1016/S0031-9422(00)98604-7

Singh, O. P., Usha, K., Saboki, E., Srivastav, M., Dahuja, A., and Singh, B. (2012). Enzymatic reactive oxygen species (ROS) scavenging system in mango varieties resistant and susceptible to malformation. Sci. Hortic. 38, 81-89. doi: 10.1016/j.scienta.2011.12.031

Soliva-Fortuny, R. C., and Martín-Belloso, O. (2003). New advances in extending the shelflife of fresh-cut fruits: a review. Trends Food Sci. Tech. 14, 341-353. doi: 10.1016/S0924-2244(03)00054-2

Subrarnaniam, R., Reinold, S., Molitor, E. K., and Douglas, C. J. (1993). Structure, inheritance, and expression of hybrid poplar (Populus trichocarpa x Populus deltoides) phenylalanine ammonia-lyase genes. Plant Physiol. 102, 71-83. doi: 10.1104/pp.102.1.71

Suleman, P., Redha, A., Afzal, M., and Al-Hasan, R. (2013). Temperature-induced changes of malondialdehyde, heat-shock proteins in relation to chlorophyll fluorescence and photosynthesis in Conocarpus lancifolius (Engl.). Acta Physiol. Plant 35, 1223-1231. doi: 10.1007/s11738-012-1161-1

Suman, K., Sugha, S. K., and Kumar, S. (2000). Role of cultural practices in the management of Septoria leaf spot of tomato. Indian Phytopath 53, 105-106.

Suzuki, N., and Mittler, R. (2006). Reactive oxygen species and temperature stresses: a delicate balance between signaling and destruction. Physiol. Plant 126, 45-51. doi: 10.1111/j.0031-9317.2005.00582.x

Takahama, U. (2004). Oxidation of vacuolar and apoplastic phenolic substrates by peroxidase: physiological significance of the oxidation reactions. Phytochem. Rev. 3, 207-219. doi: 10.1023/B:PHYT.0000047805.08470.e3

Talbi, S., Romero-Puertas, M. C., Hernández, A., Terrón, L., Ferchichi, A., and Sandalio, L. M. (2015). Drought tolerance in a Saharian plant Oudneya africana: role of antioxidant defences. Environ. Exp. Bot. 111, 114-126. doi: 10.1016/j.envexpbot.2014.11.004

Tang, K., Zhan, J. -C., Yang, H. -R., and Huang, W. -D. (2010). Changes o fresveratrol and antioxidant enzymes during UV-induced plant defense response in peanut seedlings. J. Plant Physiol. 167, 95-102. doi: 10.1016/j.jplph.2009. 07.011

Tomás-Barberán, F. A., and Espín, J. C. (2001). Phenolic compounds and related enzymes as determinants of quality in fruits and vegetables. J. Sci. Food Agr. 81, 853-876. doi: 10.1002/jsfa.885

Tommasino, E., Griffa, S., Grunberg, K., Ribotta, A., Colomba, E. L., Carloni, E., et al. (2012). Malondialdehyde content as a potential biochemical indicator of tolerant Cenchrus ciliaris L. genotypes under heat stress treatment. Grass Forage Sci. 67, 456-459. doi: 10.1111/j.1365-2494.2012.00851.x

Unlu, H., Sari, N., and Solmaz, I. (2010). Intercropping effect of different vegetables on yield and some agronomic properties. J. Food Agric. Environ. 8, 723-727.

Wada, K. C., Mizuuchi, K., Koshio, A., Kaneko, K., Mitsui, T., and Takeno, K. (2014). Stress enhances the gene expression and enzyme activity of phenylalanine ammonia-lyase and the endogenous content of salicylic acid to induce flowering in pharbitis. J. Plant Physiol. 171, 895-902. doi: 10.1016/j.jplph.2014.03.008

Wang, M., Wu, C., Cheng, Z., Meng, H., Zhang, M., and Zhang, H. (2014). Soil chemical property changes in eggplant/garlic relay intercropping systems under continuous cropping. PLoS ONE 9:e111040. doi: 10.1371/journal.pone.0111040

Wang, S. Y. (2011). "Correlation of antioxidants and antioxidant enzymes to oxygen radical scavenging activities in berries," in Berries and Cancer Prevention, eds G. D. Stoner and N. P. Seeram (New York, NY: Springer Science+Business Media, LLC).

Wei, T., Cheng, Z., Khan, M. A., Ma, Q., and Han, L. (2011). The inhibitive effects of garlic bulb crude extract on Fulvia Fulva of tomato. Pak. J. Bot. 43, 2575-2580.

Weissinger, H., Gosch, C., Abdel-Fattah, H., Spornberger, A., and Stich, K. (2013). Peroxidase activity in roots and root exudates of strawberry - linked to the resistance to root pathogens? Mitt. Klosterneuburg 4, 208-212.

Wrzaczek, M., Brosché, M., and Kangasjärvi, J. (2013). ROS signaling loops production, perception, regulation. Curr. Opin. Plant Biol. 16, 575-582. doi: 10.1016/j.pbi.2013.07.002

Wu, W., Hua, Y., and Lin, Q. (2014). Effects of oxidative modification on thermal aggregation and gel properties of soy protein by malondialdehyde. J. Food Sci. Tech. Mys. 51, 485-493. doi: 10.1007/s13197-011-0533-7

Xiao, X. M., Cheng, Z. H., and Meng, H. W. (2012). Intercropping with garlic alleviated continuous cropping obstacle of cucumber in plastic tunnel. Acta Agr. Scand B-S Plant 62, 696-705. doi: 10.1080/09064710.2012.697571

Yamauchi, Y., Furutera, A., Seki, K., Toyoda, Y., Tanaka, K., and Sugimoto, Y. (2008). Malondialdehyde generated from peroxidized linolenic acid causes protein modification in heat-stressed plants. Plant Physiol. Biochem. 46, 786-793. doi: 10.1016/j.plaphy.2008.04.018

Yin, X. M., Huang, L. F., Zhang, X., Wang, M. L., Xu, G. Y., and Xia, X. J. (2015). OsCML4 improves drought tolerance through scavenging of reactive oxygen species in rice. J. Plant Biol. 58, 68-73. doi: 10.1007/s12374-014-0349-x

Yu, B., Zhang, D., Huang, C., Qian, M., Zheng, X., Teng, Y., et al. (2012). Isolation of anthocyanin biosynthetic genes in red Chinese sand pear (Pyrus pyrifolia Nakai) and their expression as affected by organ/tissue, cultivar, bagging and fruit side. Sci. Hortic. 136, 29-37. doi: 10.1016/j.scienta.2011.12.026

Zhang, S., Hua, B., and Zhang, F. (2008). Induction of the activities of antioxidative enzymes and the levels of malondialdehyde in cucumber seedlings as a consequence of Bemisia tabaci (Hemiptera: Aleyrodidae) infestation. Arthropod-Plant Inte. 2, 209-213. doi: 10.1007/s11829-008-9044-5

Zhang, Z. (2004). The Guidance of Plant Physiology Experiments. Beijing: Chinese agricultural science and technology press.

Zheng, L., Zhong, G., and Zhang, S. (2007). PPO activity determination and antibrowning measure for amorphophallus albus. Chinese J. Southwest University (Natural Science Edition) 29, 118-121.

Conflict of Interest Statement: The authors declare that the research was conducted in the absence of any commercial or financial relationships that could be construed as a potential conflict of interest.

Copyright (c) 2015 Wang, Wu, Cheng and Meng. This is an open-access article distributed under the terms of the Creative Commons Attribution License (CC BY). The use, distribution or reproduction in other forums is permitted, provided the original author(s) or licensor are credited and that the original publication in this journal is cited, in accordance with accepted academic practice. No use, distribution or reproduction is permitted which does not comply with these terms. 